\title{
Anatomy of the Male Reproductive Organs of Javan Pangolin (Manis javanica)
}

\author{
Yusrizal Akmal ${ }^{1,2 *}$, Chairun Nisa', Savitri Novelina ${ }^{3}$ \\ ${ }^{1}$ Study Program of Anatomy and Animal Development, Post Graduate School, Bogor Agricultural \\ University \\ ${ }^{2}$ Study Program of Animals Husbandry, Al Muslim University of Peusangan, \\ Jln. Al Muslim, Matangglumpangdua (Bireuen), Aceh 24261 \\ ${ }^{3}$ Departement of Anatomy, Physiology and Pharmacology. Faculty of Veterinary Medicine, \\ Bogor Agricultural University. Jl. Agatis Kampus IPB Dramaga Bogor 16680 \\ *Corresponding author: drh_yusrizalakmal@yahoo.com
}

Key words: pangolin (M. javanica), male reproductive organs, ascrotal testes, accessories gland

\section{INTRODUCTION}

Pangolin is an animal that has special attention by CITES since 1985 . This is due to increase of market demand, especially from China. It causes the illegal hunting is increasing, so that alleged wild population decreases dramatically. Overcoming of decreasing of the pangolin populations in the wild, could be anticipated by captive breeding. The information about the status of the reproductive biology of wild animals is very important for implementation of ex situ conservation activities. One of the aspects of the reproductive biology of wild animals is knowledge of the anatomy and physiology of the reproductive organs both males and females.

Nowdays, data on morphological characteristics of male reproductive organs of pangolin $(M$. javanica) still limited. The data obtained of this study is new information in reproductive biology, especially on the morphological characteristics of the male reproductive organs of pangolin $(M$. javanica). In addition, the information can be the data base that is important in the effort to support ex situ conservation.

\section{MATERIALS AND METHODS}

This study was used the male reproductive organs of five pangolin ( $M$. javanica). Macroscopic observations carried out on in situ position, shape and size of the male reproductive organs, includes the testes, reproductive tract, accessories gland and penis. Body weight measured using large scales and testes using analytical scales Ohause ${ }^{\circledR}$ with a capacity of $200 \mathrm{~g}$. Measurement of length, diameter/width and thickness using caliper in $\mathrm{cm}$. All observations are documented using a digital camera Canon EOS 400D. The results were analyzed descriptively and presented in the form of tables and figures.

\section{RESULTS AND DISCUSSION}

Male reproductive organs of pangolin consist of the ascrotal testes, epididymis which can be described as head, body and tail, deferent duct, and urethra contained within the penis. All organ were paired, except the penis. Morphometry of the male reproductive organs of pangolin were presented in Table 1.

Pangolin has a pair of ascrotal testes (Figure 1A), an oval in shape an located subcutis of inguinal area beneath of a thick $\mathrm{m}$. cutaneous. It was interesting result that should be noteworthy, because generally the mammalian male have scrotum. Pangolin are nocturnal animals and have a relatively low body temperature ranges $33-34.5^{\circ} \mathrm{C}$ [1], compared to general mammals. Therefore, the absence of scrotum on pangolin allegedly had little influence on the process of spermatogenesis of these animals. Additionally, rolling up the body into ball is one of pangolin behaviour, so that the presence of ascrotal testes will not disrupt their activities. Other mammals with ascrotal testes are some animals of the order Eulipotyphla (hedgehogs), Cetacea (whales) and Pholidota (pangolin), as well as from family Rhinocerotidae (rhinoceros), Tapiridae (tapirs), Hippopotamidae (hippopotamus), Phocidae (seals) and Odobaenidae (walruses) [2]. 
Table 1. Morphometry of the male reproductive organs of pangolin

\begin{tabular}{|c|c|c|c|c|c|c|c|c|}
\hline \multirow{3}{*}{$\begin{array}{c}\text { Reproductive } \\
\text { Organs* }\end{array}$} & \multicolumn{8}{|c|}{ Parameter Measurement } \\
\hline & \multicolumn{2}{|c|}{ Length (cm) } & \multicolumn{2}{|c|}{$\begin{array}{l}\text { Diameter/ width } \\
(\mathrm{cm})\end{array}$} & \multicolumn{2}{|c|}{ Thickness (cm) } & \multicolumn{2}{|c|}{ Weight (g) } \\
\hline & Right & Left & Right & Left & Right & Left & Right & Left \\
\hline Testis & $3.69 \pm 0.74$ & $3.86 \pm 0.76$ & $1.25 \pm 0.09$ & $1.23 \pm 0.13$ & $0.88 \pm 0.21$ & $0.92 \pm 0.15$ & $5.61 \pm 1.90$ & $5.66 \pm 1.92$ \\
\hline Mean & \multicolumn{2}{|c|}{$3.78 \pm 0.12$} & \multicolumn{2}{|c|}{$1.24 \pm 0.02$} & \multicolumn{2}{|c|}{$0.90 \pm 0.03$} & \multicolumn{2}{|c|}{$5.64 \pm 0.04$} \\
\hline Epididymis & $4.79 \pm 2.33$ & $4.76 \pm 2.09$ & $0.36 \pm 0.06$ & $0.39 \pm 0.05$ & & & & \\
\hline Mean & \multicolumn{2}{|c|}{$4.78 \pm 0.02$} & \multicolumn{2}{|c|}{$0.38 \pm 0.02$} & \multicolumn{2}{|c|}{-} & & \\
\hline Deferent duct & \multirow{2}{*}{\multicolumn{2}{|c|}{$\begin{array}{c}8.75 \pm 7.67 \quad 9.19 \pm 7.97 \\
8.98 \pm 0.31\end{array}$}} & \multicolumn{2}{|c|}{-} & \multicolumn{2}{|c|}{-} & \multicolumn{2}{|c|}{-} \\
\hline Mean & & & \multirow{2}{*}{\multicolumn{2}{|c|}{$064+003$}} & \multirow{2}{*}{\multicolumn{2}{|c|}{-}} & \multicolumn{2}{|c|}{ - } \\
\hline Penis & \multicolumn{2}{|c|}{$5.39 \pm 1.63$} & & & & & \multicolumn{2}{|c|}{-} \\
\hline
\end{tabular}

* Samples reproductive organs that have been fixed and the sign (-) not measured
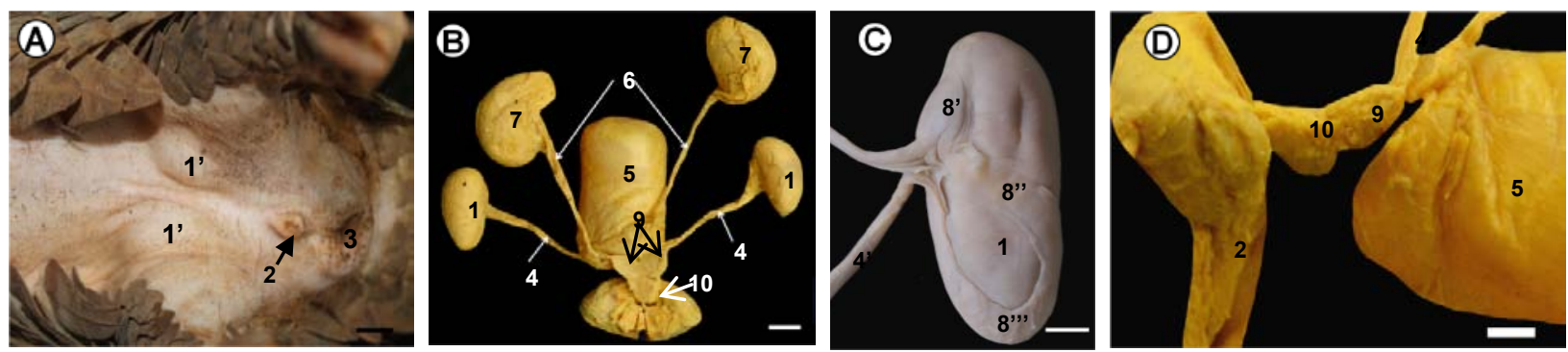

Figure 1. A. A pair of ascrotal testes (1) in inguinal area with the position of the small penis (2) in the perineal area of ventral anus (3). B. reproductive organs after being removed from the body cavity at dorsal view. A pair of testis (1) connected by deferent duct (4') and runs in the spermatic cord (4) empties into the urethra at the base of bladder (5) together with the ureter (6) derived from a pair of kidneys (7). C. Epididymis (8) formed head (8'), body (8") dan tail epididymidis (8"') and runs oblique mediodistal on dorsal testis. D. Accessory gland consists of vesicular gland (9), dan prostate (10) Bar: $A=2 \mathrm{~cm}, B$ and $D=1 \mathrm{~cm}, C=0.5 \mathrm{~cm}$.

The accessories gland of pangolin consisted of vesicular gland, prostate and bulbourethral glands. The vesicular gland located at the base of the right and left ampulla (Fig. 1B, 1D). The prostate was observed on the base of both vesicularis gland as thickened at the base of the urethra (Fig. 1B, 1D). While the bulbourethral glands was not observed macroscopically. It was covered by muscles in the radix penis and attaches to the anal glands which located in the left and right perianal region. The penis of pangolin located on the perineum and directed cranioventrad (Fig. 1A). The penis was small with the shape of glans was tapering and lies within preputial cavity. The crus of penis has two roots which were attached to the pubic bone while the dorsal part was attached to the anal glands.

\section{CONCLUSION}

The male reproductive organs of pangolin consisted a pair of ascrotal testes located in subcutis of inguinal area. The shape and size of the right and left testes were relatively equal, oval-shaped. The head, body and tail epididymis positioned oblique mediodistal on dorsal testis. The accessories gland consisted pair of the vesicular and bulbourethral glands, and a single prostate. The found of the ascrotal testes was interesting result of this study and thought to be related to the behavior of pangolin to roll up the body.

\section{REFERENCES}

[1] Heath ME. 1992. Mammalian species: Manis pentadactyla. The American Society of Mammalogists 14: 1-6.

[2] Kleisner K, Ivell R, Flegr J. 2010. The evolutionary history of testicular externalization and the origin of the scrotum. J Biosci 35: 27-37. 